\title{
Long-term persisting hybrid swarm and geographic difference in hybridization pattern: genetic consequences of secondary contact between two Vincetoxicum species (Apocynaceae- Asclepiadoideae)
}

Yue Li ${ }^{i^{*}}$, Fumito Tada ${ }^{2}$, Tadashi Yamashiro ${ }^{3}$ and Masayuki Maki ${ }^{1}$

\begin{abstract}
Background: During glacial periods, glacial advances caused temperate plant extirpation or retreat into localized warmer areas, and subsequent postglacial glacial retreats resulted in range expansions, which facilitated secondary contact of previously allopatric isolated lineages. The evolutionary outcomes of secondary contact, including hybrid zones, dynamic hybrid swarm, and resultant hybrid speciation, depends on the strengths of reproductive barriers that have arisen through epistatic and pleiotropic effects during allopatric isolation. The aim of this study was to demonstrate refugia isolation and subsequent secondary contact between two perennial Asclepioid species and to assess the genetic consequences of the secondary contact. We modeled the range shift of two ecologically distinct Vincetoxicum species using the species distribution model (SDM) and assessed the genetic consequences of secondary contact by combining morphological and genetic approaches. We performed morphometric analysis (592 individuals) and examined 10 nuclear microsatellites (671 individuals) in V. atratum, V. japonicum, and putative hybrid populations.

Results: Multivariate analysis, model-based Bayesian analysis, and non-model-based discriminant analysis of principal components confirmed the hybridization between $V$. atratum and $V$. japonicum. High pollen fertility and a lack of linkage disequilibrium suggested that the hybrid populations may be self-sustaining and have persisted since $V$. atratum and $V$. japonicum came into contact during the post-glacial period. Moreover, our findings show that the pattern of hybridization between $V$. atratum and $V$. japonicum is unidirectional and differs among populations. Geographically-isolated hybrid populations exist as genetically distinct hybrid swarms that consist of $V$. atratum-like genotypes, $V$. japonicum-like genotypes, or admixed genotypes. In addition, Bayesian-based clustering analysis and coalescent-based estimates of long-term gene flow showed patterns of introgressive hybridization in three morphologically 'pure' $V$. japonicum populations.

(Continued on next page)
\end{abstract}

\footnotetext{
* Correspondence: yueli@life.biology.tohoku.ac.jp

'Botanical Gardens, Tohoku University, Sendai, Aoba 980-0862, Japan

Full list of author information is available at the end of the article
} 
(Continued from previous page)

Conclusion: In this study, we demonstrated that climatic oscillations during the Quaternary period likely led to species range shift and subsequently secondary contact. Hybrid populations may be self-sustaining and have persisted since $V$. atratum and $V$. japonicum came into contact during the post-glacial period. Pattern of hybridization between $V$. atratum and $V$. japonicum is unidirectional and differs among populations. We concluded that these differences in the genetic consequences of secondary contact are caused by historical colonization processes and/or natural selection.

Keywords: Historical introgression, Hybrid swarm, Nuclear microsatellite, Past secondary contact, Vincetoxicum

\section{Background}

In response to climatic oscillations over the last 2 million years (Ma), the geographical distributions of temperate plants have been subject to multiple contractions and expansions [1]. During glacial periods, glacial advances caused temperate plant extirpation or retreat into localized warmer areas, and subsequent postglacial glacial retreats resulted in range expansions, which facilitated secondary contact of previously allopatric isolated lineages [2-4]. The evolutionary outcomes of secondary contact, including hybrid zones, dynamic hybrid swarm, and resultant hybrid speciation [5], depend on the strengths of reproductive barriers [6].

Assuming that the reproductive isolation between two species coming into contact was incomplete, first generation hybrids may mate with parental species. Frequently backcrossing between hybrids and their parental species will lead introgression of alleles across species boundaries, thereby affecting species history and delimitation [7]. The dynamics of introgression for neutral alleles are thought to be depends on the reproductive system of the interacting taxa [8-11], but also on relative population abundance [12]. Genes are assumed to flow from large populations of one species into much smaller populations. Recent theoretical models predicted that the direction of introgression of neutral alleles between lineages should proceed from the locally established species towards the expanding congener $[13,14]$. In addition, genotype combinations might be filtered by selection factors that vary with the surroundings (genotype-by-environment interactions) [15-22].

In recent years, an increasing number of studies have employed species distribution modeling (SDM) or ecological niche modeling (ENM) to support refugia isolation and subsequent range expansion and corroborate phylogenetic approaches. The aim of this study was to demonstrate refugia isolation and subsequent secondary contact by modeling range shifts. This study presents one of the first applications of the species distribution model (SDM) to explain the direction of historical gene flow and its effects on the genetic consequences of secondary contact by predicting potential glacial distribution and postglacial colonization processes.
The Japanese Archipelago is thought to have been free of massive ice sheets during the last glacial maximum (LGM) with the exception of some high altitude areas [23]. Previous phylogenetic studies showed that the postglacial range expansion process may have caused secondary contact between formerly isolated lineages of Fagus crenata [24], Aesculus turbinata [25], Padus grayana, Euonymus oxyphyllus, Magnolia obovata, Carpinus tschonoskii, C. japonica, C. laxiflora [26], Platycrater arguta [27], Rubus palmatus, and R. grayanus [28]. Two ecologically distinct species of Vincetoxicum (ApocynaceaeAsclepiadoideae), $V$. atratum (Bunge) Morren et Decaisne and $V$. japonicum Morren et Decne., provide a suitable study system. Because the different habitat preferences of the species may result in different responses to climate change [3, 29-31], V. atratum and $V$. japonicum may have retreated into separate refugia during the glacial period and subsequent postglacial expansion may have facilitated secondary contact, resulting in hybridization.

Vincetoxicum atratum and V. japonicum are perennial herbs. Vincetoxicum atratum is distributed across the Sino-Japanese region including the Japanese Archipelago, Korean Peninsula, and China, whereas $V$. japonicum is distributed in the Japanese Archipelago and the Korean Peninsula [32]. In Japan, $V$. atratum is found in grasslands or meadows across northern to southern regions of the archipelago, while $V$. japonicum is found in sunny meadows or on rocky beaches near seashores of central and southern regions of the archipelago [32]. Because the habitat area has diminished due to habitat destruction and degradation, the number and sizes of $V$. atratum populations have decreased rapidly. Morphologically, the two species can be distinguished based on specific characteristics. Vincetoxicum atratum has a purple corolla, which is pubescent outside and glabrous inside, while $V$. japonicum has a yellowish white corolla, which is glabrous outside and pubescent inside. Leaves of $V$. atratum are villous on both sides while those of $V$. japonicum are densely pubescent [32]. The flowering periods of these species partially overlap in early summer. Some dipteran species are pollinators of both $V$. atratum and $V$. japonicum [33]. The low level of genetic diversification in the chloroplast DNA (cpDNA) of the two 
species in contrast with the considerable morphological divergence suggests that the species have undergone rapid morphological divergence [34].

In this study, we examined past hybridization and introgression between $V$. atratum and $V$. japonicum by combining morphological and genetic approaches with paleoclimatic analysis. First, we examined the hybrid status of individuals from seven morphologically putative hybrid populations using a morphometric approach. Second, we examined the genetic structure of morphologically 'pure' $V$. atratum, $V$. japonicum, and putative hybrid populations. In particular, we examined deviation from linkage equilibrium for nuclear microsatellite markers because linkage disequilibrium would be expected in a hybrid zone as a result of ongoing gene flow between the parent species [35-37]. Third, we predicted species paleo-distributions in response to the Quaternary climate change to model range shifts of $V$. atratum and $V$. japonicum and to infer past opportunities for secondary contact between the species. In this report, we address the following three questions. (1) What are the genetic and phenotypic patterns of morphologically 'pure' $V$. atratum, $V$. japonicum, and putative hybrid populations? (2) What is the outcome of secondary contact between $V$. atratum and $V$. japonicum? (3) What is the genetic consequence of hybridization between the two species?

\section{Methods}

\section{Study site and sampling}

We sampled morphologically 'pure' populations of $V$. atratum and $V$. japonicum from almost the entire ranges of the two species in Japan (Fig. 1; Additional file 1: Table S1). Seven morphologically hybrid populations between $V$. atratum and $V$. japonicum were sampled (Fig. 1; Additional file 1: Table S1). Morphologically hybrid populations were tentatively identified based on the corolla color and vestiture on leaves. We did not detect morphologically 'pure' populations of $V$. atratum and $V$. japonicum near any of the tentative hybrid populations. Leaf samples of individuals, separated by at least $2 \mathrm{~m}$, were collected to avoid resampling the same genotypes. The leaf samples were stored at $-70{ }^{\circ} \mathrm{C}$ until DNA extraction.

\section{DNA extraction and nuclear microsatellite scoring}

Total DNA was extracted from approximately $100 \mathrm{mg}$ of leaf tissue based on the method of Maki, Horie and Yokoyama [38]. Ten nuclear simple sequence repeat (nrSSR) loci including vinc5, vinc107, vinc118 [39], Vpy 012, Vpy 013, Vpy 016, Vpy 018, Vpy 022 [40], Vkat3, and Vkat2 (Yamashiro et al., unpublished,) were scored. These 10 loci were amplified in three multiplex reactions (Additional file 1: Table S2). Multiplex PCRs were performed in $3-\mu \mathrm{L}$ volumes containing approximately $50 \mathrm{ng}$ genomic DNA, $1 \times$ Type-it Multiplex PCR Master Mix (QIAGEN), and $0.2 \mu \mathrm{M}$ each of forward and reverse primers. The reaction parameters were an initial denaturation step at $95{ }^{\circ} \mathrm{C}$ for 5 min followed by 26 cycles at $95{ }^{\circ} \mathrm{C}$ for $30 \mathrm{~s}, 60{ }^{\circ} \mathrm{C}$ for $90 \mathrm{~s}$, and $72{ }^{\circ} \mathrm{C}$ for $60 \mathrm{~s}$, and a final step at $60{ }^{\circ} \mathrm{C}$ for $30 \mathrm{~min}$. PCR products were run with an internal size standard GeneScan LIZ-600 (Applied Biosystems) on an ABI 3100 Genetic Analyzer (Applied Biosystems). Allele sizes were scored using GENEMAPPER v3.7 software (Applied Biosystems).

\section{Morphological measurements}

Morphological measurements were performed on the same individuals that were genotyped. The four largest mature leaves and four largest mature flowers of each individual were subjected to measurement of morphological characteristics and the averages of the measurements per individual were used for morphometric analyses. A total of 13 quantitative and four semi-quantitative characteristics were measured (Fig. 2; Table 1).

\section{Morphometric analysis}

For 13 continuous variables, significant differences between allopatric $V$. atratum and $V$. japonicum were tested using one-way analysis of variance (ANOVA). Pearson correlation coefficients were calculated to eliminate highly correlated (Pearson's correlation $>0.9$ ) characteristics from further analyses. A Kolmogorov-Smirnov test was used to determine whether the data met the assumption of normal distribution, while a Levene's test was used to test for homoscedasticity. For four ordinal variables, Kruskal-Wallis one-way ANOVA was performed to estimate differences between $V$. atratum and $V$. japonicum. Principal coordinate analysis ( $\mathrm{PCO}$ ) was used to visualize morphological variation among morphologically 'pure' $V$. atratum, $V$. japonicum populations and morphologically hybrid populations. All statistical analyses were performed using $\mathrm{R}$ programming language [41].

\section{Pollen viability estimation}

Pollen fertility was examined in three populations of $V$. atratum (A01-A03) and V. japonicum (J01-J03) and in all putative hybrid populations following the procedure of [42].

\section{Population genetic analysis}

For each population, the mean number of alleles per locus $\left(N_{\mathrm{a}}\right)$, observed heterozygosity $\left(H_{\mathrm{O}}\right)$, and expected heterozygosity $\left(H_{\mathrm{E}}\right)$ were calculated using the program GenAlEx version 6 [43]. Allelic richness (AR) and private allele richness (PAR) were estimated using HPRARE 1.1 software [44]. Genetic differentiation in all pair wise combinations of the populations was estimated from the fixation index $\left(F_{\mathrm{ST}}\right.$, [45] for nuclear simple sequence repeats (nrSSRs) with 1000 permutations using 


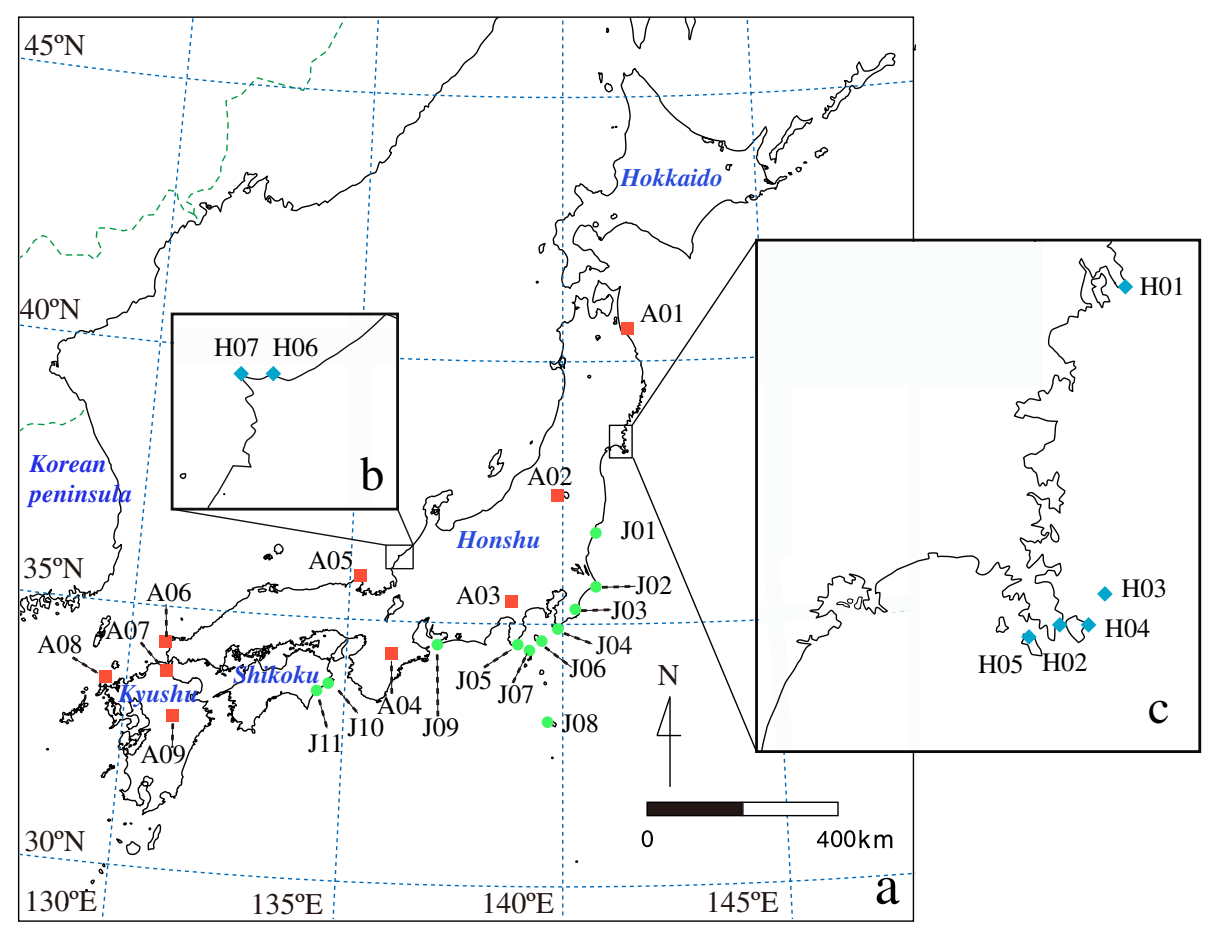

Fig. 1 Maps of the hybrid zone between $V$. atratum and $V$. japonicum and of morphologically 'pure' $V$. atratum populations. a Map of Japan showing locations of the hybrid zone and morphologically 'pure' $V$. atratum populations (filled red cube) and $V$. japonicum populations (filled green circles). b, c Detailed map of the hybrid zones showing the putative hybrid sampling sites (blue diamond). Additional details for each population are shown in Additional file 1: Table S1

Arlequin version 3.5 software [46]. Tests for deviation from the Hardy-Weinberg equilibrium (HWE) at each locus were conducted with Arlequin version 3.5 software using 10,000 permutations [46]. Tests for the linkage disequilibrium (LD) of all combinations of the loci for each population were conducted using GENEPOP 4.2 software [47]. LD can be induced by genetic admixture between divergent gene pools $[35,36]$ and will decay if gene flow occurs between the divergent gene pools [37], thus, if no pair wise LD was detected among loci, we would expect that the hybrid population would not be maintained by ongoing gene flow.

\section{Bayesian admixture analysis}

A Bayesian model-based approach implemented in the program STRUCTURE version 2.2.3 [48] and TESS version 2.3 software [49] was used to assess the genetic delimitation between $V$. atratum and $V$. japonicum and to estimate the proportion of each individual genome originating from each of the parental populations. We assigned individuals having an assignment value $(q)$ greater than 0.9 into one of the parental lineages and classified those with values less than 0.9 as hybrids. For analysis using STRUCTURE, different probable numbers of genetic clusters $(K)$ were estimated for all samples under the admixture model with correlated allele frequencies. Ten replicate runs were performed for each value of $K$ ranging from 1 to 10. Each run included a burn-in of 10,000 steps followed by 100,000 Markov chain Monte Carlo (MCMC) simulations. The optimal value of $K$ was calculated using the STRUCTURE HARVESTER program [50]. The results from the 10 replicates of the optimal value of $K$ were averaged using the CLUMPP program [51] and were visualized using the DISTRUCT 1.1 program [52].

TESS version 2.3 was used to estimate population structure by incorporating geographical coordinates of individuals as prior information to detect discontinuities in allele frequencies [49]. The analyses were performed using a conditional autoregressive (CAR) model with a burn-in of 10,000 iterations followed by 60,000 iterations for each $K$ value (the number of clusters) between 2 and 10 . The optimal value of $K$ was determined based on the lowest value of the deviance information criterion (DIC). The results from the 10 replicates with the lowest DIC values were averaged using CLUMPP [51] and were visualized using DISTRUCT 1.1 as in the STRUCTURE analyses [52].

\section{Discriminant analysis of principal components}

To detect complex genetic structure, a non-model-based discriminant analysis of principal components (DAPC) using the adegenet version 1.2.8 package [53] in $\mathrm{R}$ [41] 


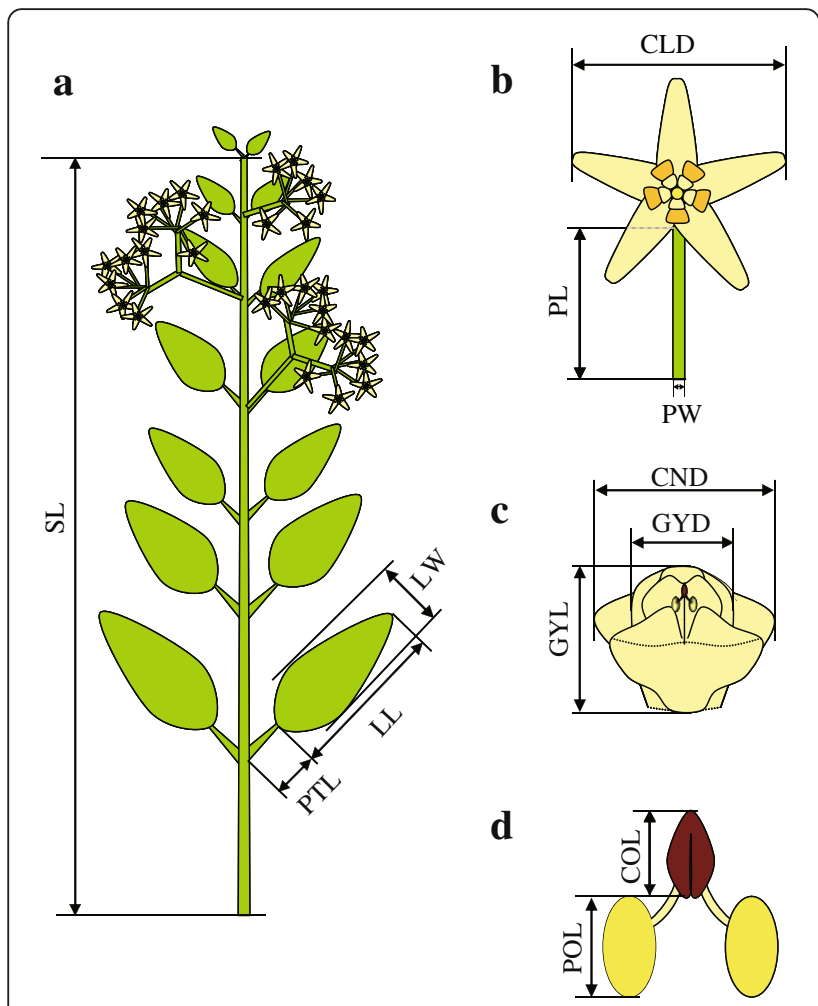

Fig. 2 Schematic diagrams showing the morphological characteristics measured and used in the morphometric analyses

was conducted based on the SSR data set. The prior clusters were defined by the groups obtained from each population. DAPC first transforms genotype into uncorrelated components using principle component analysis (PCA) and then performs a discriminant analysis on the retained principle components (PCs).

\section{Estimation of long-term gene flow}

We divided studied populations based on the genetic constitution of each population defined by STRUCTURE, namely, 'pure' $V$. atratum (A01-A07 and A09), 'pure' $V$. japonicum (J01-J08), south group of putative hybrid population (H01-H05), north group of putative hybrid population ( $\mathrm{H} 06-\mathrm{H} 07)$ and introgressed $V$. japonicum (J09-J11). We estimated bidirectional long-term migration rates among the five categories based on $10 \mathrm{nrSSR}$ loci with a coalescent-based model implemented in the LAMARC 2.1 program [54]. We randomly picked genotype data for 20 individuals in each categories, because migrate history in additional individuals is probably similar to that of its cohorts. We estimated impacts of migration relative to mutation rate $(M=m / \mu)$ and the mutation-scaled effective population size $\left(\Theta=4 N_{e} \mu\right)$. $N_{e}$ is the effective population size, $m$ is the migration rate between two populations, and $\mu$ is the mutation rate per generation at the locus considered. We used logarithmic prior distributions for migration rate $(0.01,3000)$, and effective population size $(0.00001,10)$. We conducted Bayesian analyses under the Brownian motion model [55]. Search parameters consisted of 10 initial chains with 5,000 samples, a sampling interval of 30 (150,000 steps), and a burn-in of 10,000 samples; two final chains with 50,000 samples and a sampling interval of 30 (1,500,000 steps); and a burn-in of 200,000 samples. For each pair wise comparison $(i \rightarrow j)$, the number of immigrants from population $i$ into population $\mathbf{j}\left(N_{e} m_{(i \rightarrow j)}\right)$ was estimated from $N_{\mathrm{e}} m=\Theta_{i}^{*} M_{(i \rightarrow j)} / 4$, where $\Theta$ represents the mutation scaled effective population size $\left(\Theta=4 N_{e} \mu\right)$. Results are reported as most probable estimates (MPE) with $95 \%$ confidence intervals (CIs). We used Tracer v1.6 [56] to confirm sampling adequacy and convergence of parameters. All parameter estimates were well supported, with ESS (effective sample size) values exceeding 200.

\section{Species distribution modeling}

We used species distribution modeling (SDM) to identify the range of suitable habitats of $V$. atratum and $V$. japonicum during three periods, namely, the present, the midHolocene $(6,000 \mathrm{ybp})$, and the last glacial maximum (LGM; 21,000 ybp). The maximum entropy algorithm (MAXENT, Phillips and Dudík; 2008), based on presenceonly data, and the associated environmental covariates were used to model species distribution. Species occurrence data were collected from the S-Net data portal (http://science-net.kahaku.go.jp/) and our sampling locations (Additional file 1: Table S3). We restricted the spatial extent of the modeled area to only Japanese Archipelago for both species. SDM was constructed using information for $125 \mathrm{~V}$. atratum and $128 \mathrm{~V}$. japonicum sites to predict the geographic distributions of each species (Additional file 1: Table S3; Additional file 1: Figure S1). Collection coordinates were plotted in Google Earth (http://earth.google.com) to confirm that each set represented a reasonable location. A total of 19 environmental variables (Additional file 1: Table S4) were downloaded from the WorldClim website (www.worldclim.org; [57]. We extracted the values of each of the 19 environmental variables for all occurrence recorder points using the DIVA-GIS program [58] and examined pair wise correlations using $\mathrm{R}$ [41]. After evaluation, variables with low pair wise Pearson correlation coefficients $(r<0.70)$ were used for subsequent analyses (Additional file 1: Table S3). We used the simulation summaries of the Community Climate System Model version 4 (CCSM4) to create mid-Holecene and LGM climate data projections. The resolutions of current, mid-Holecene, and LGM climate layers were 30 arcsec, 30 arcsec, and 2.5 arcmin, respectively. The distributional model for each species was generated using MAXENT 3.3.3 k [59] and included $75 \%$ of species 
Table 1 Description of the morphological characteristics scored for morphologically 'pure' $V$. atratum and $V$. japonicum plants and morphologically intermediate plants, and the results of one way ANOVA or Kruskal-Wallis ANOVA of morphologically 'pure' V. atratum and $V$. japonicum plants

\begin{tabular}{|c|c|c|c|}
\hline Morphological characteristic & Label & Trans. & Species $\mathrm{F}(\mathrm{dF}=1)$ \\
\hline Maximum leaf blade length $(\mathrm{cm})$ & $\mathrm{LL}$ & None & $127.70^{* * *}$ \\
\hline Maximum leaf blade width $(\mathrm{cm})$ & LW & None & $34.89^{* * *}$ \\
\hline Petiole length $(\mathrm{cm})$ & PL1 & None & 0.03 \\
\hline Stem length $(\mathrm{cm})^{\mathrm{a}}$ & SL & $\log$ & 2.12 \\
\hline Hair density on adaxial leaf surface $(\mathrm{cm})^{b}$ & $\mathrm{HDL}$ & None & $* * *$ \\
\hline Hair density on abaxial leaf surface $(\mathrm{cm})^{c}$ & $\mathrm{HBL}$ & None & $* * *$ \\
\hline Number of flowers & NF & None & $5.41^{*}$ \\
\hline Pedicel length (cm) & $P L$ & None & $5.08^{*}$ \\
\hline Pedicel width $(\mathrm{cm})$ & PW & None & $1371.00^{* * *}$ \\
\hline Corolla diameter $(\mathrm{cm})$ & CLD & None & $649.10^{* * *}$ \\
\hline Hair density on corolla outside $(\mathrm{cm})^{d}$ & $\mathrm{HCO}$ & None & $* * *$ \\
\hline Hair density on corolla inside $(\mathrm{cm})^{\mathrm{e}}$ & $\mathrm{HCl}$ & None & $* * *$ \\
\hline Corona diameter $(\mathrm{cm})$ & CND & None & $1882.00^{* * *}$ \\
\hline Gynostegium length (cm) & GYL & None & $2027.00^{* * *}$ \\
\hline Gynostegium diameter (cm) & GYD & None & $2913.00^{* * *}$ \\
\hline Corpusculum length (cm) & $\mathrm{COL}$ & None & $1154.00^{* * *}$ \\
\hline Pollinia length (cm) & POL & None & $378.30^{* * *}$ \\
\hline
\end{tabular}

${ }^{\mathrm{a}}$ Trans. = transformations applied to achieve normality and homogeneity of variances (Log $=$ Natural Logarithm)

${ }^{b}$ Ordinal grades $1-10.1=$ less than $20,2=21-40,3=41-60,4=61-80,5=81-100,6=101-120,7=121-140,8=141-160,9=161-180$, and $10=181-200\left(\right.$ hairs $\left./ \mathrm{cm}^{2}\right)$

cOrdinal grades $1-10.1=$ less than $40,2=41-80,3=81-120,4=121-160,5=161-200,6=201-240,7=241-280,8=281-320,9=321-360$, and $10=361-400$ (hairs $/ \mathrm{cm}^{2}$ )

${ }^{\mathrm{d}}$ Ordinal grades $1-10.1$ = less than $10,2=11-20,3=21-30,4=31-40,5=41-50,6=51-60,7=61-70,8=71-80,9=81-90$, and $10=91-100\left(\right.$ hairs $/ \mathrm{cm}^{2}$ )

${ }^{\mathrm{e}}$ Ordinal grades $1-10.1=$ less than $10,2=11-20,3=21-30,4=31-40,5=41-50,6=51-60,7=61-70,8=71-80,9=81-90$, and $10=91-100\left(\right.$ hairs $/ \mathrm{cm}^{2}$ )

$* P<0.05, * * P<0.01, * * * P<0.001$

records for training and $25 \%$ for testing the model. We employed receiver operating characteristic (ROC) analysis to measure model performance [60]. The accuracy of each model prediction was tested by the area under the ROC curve (AUC) [61]. AUC scores range from 0 to 1 , with a score greater than 0.7 considered to be a good model performance [62].

\section{Results}

\section{Morphological differentiation}

Hair density on the abaxial leaf surface (HBL), hair density on the adaxial leaf surface (HDL), and hair density on the corolla outside (HCO) were highly correlated with each other $(r>0.9)$, and thus HBL and HCO were eliminated from subsequent multivariate analyses. Three vegetative characteristics, maximum leaf blade length (LL), maximum leaf blade width (LW), and hair density on the adaxial leaf surface (HDL), and eight floral characteristics, pedicel width (PW), corolla diameter (CLD), hair density on the corolla inside ( $\mathrm{HCI})$, corona diameter (CND), gynostegium length (GYL), gynostegium diameter (GYD), corpusculum length $(\mathrm{COL})$, and pollinia length $(\mathrm{POL})$ that exhibited significant differences $(P<0.05)$ among morphologically 'pure' $V$. atratum and $V$. japonicum populations (Table 1) were used for multivariate analyses. Inter- and intra-population variations in these morphological characteristics are shown in box plots (Additional file 1: Figure S2) and bar plots (Additional file 1: Figure S3). The intra-population variation range for these characteristics varied among putative hybrid populations. For example, PW values of the H01 population tended to be similar to those of $V$. atratum, whereas the $\mathrm{PW}$ values of the $\mathrm{H} 02-\mathrm{H} 05$ populations tended to be similar to those of $V$. japonicum. The ranges of variation in PW in the $\mathrm{H} 06$ and $\mathrm{H} 07$ populations were intermediate between those of $V$. atratum and $V$. japonicum.

\section{Multivariate analysis}

The first and second axes in principal coordinate (PCO) analysis accounted for 55.94 and $10.26 \%$ of the total variance, respectively (Fig. 3). The PCO analysis showed two distinct groups of clearly separating, morphologically 'pure' $V$. atratum and $V$. japonicum individuals along the first axis. In the putative hybrid populations, individuals of the $\mathrm{H} 01$ population were largely distributed over the range of variation of phenotypes of 'pure' 
$V$. atratum, as well as intermediate positions between those of the two species. Individuals of the H02 and H03 populations were largely distributed over the range of variation of phenotypes of 'pure' $V$. japonicum, as well as intermediate positions. Individuals of the $\mathrm{H} 05$ population overlapped with the range of variation of phenotypes of 'pure' $V$. japonicum. Individuals of the H04, $\mathrm{H} 06$, and $\mathrm{H} 07$ populations were mostly distributed over intermediate positions between the two species.

\section{Pollen fertility}

The minimum, maximum, and median values of pollen fertility are summarized in Additional file 1: Table S5. All the populations examined exhibited high pollen fertility. Pollen fertility ranged from $97-100 \%$ in $V$. atratum populations (A01-A03), 96-100 \% in hybrid populations (H01-H07), and $100 \%$ in $V$. japonicum populations (J01-J03).

\section{Microsatellite diversity}

A total of 144 alleles were found for $10 \mathrm{nrSSR}$ loci in $V$. atratum populations compared with 165 alleles for $V$. japonicum. The mean number of alleles per locus $\left(N_{\mathrm{a}}\right)$ within a population was 5.30-8.10 in $V$. atratum and 2.60-8.90 in V. japonicum (Additional file 1: Table S1). The allele richness and the expected heterozygosity were 3.89-4.82 and 0.597-0.697, respectively, in $V$. atratum, and 2.06-4.34 and 0.289-0.667, respectively, in $V$. japonicum (Additional file 1: Table S1). While most of the loci were in Hardy-Weinberg equilibrium (HWE), 31 of 260 cases showed significant deviations from HWE expectation (Additional file 1: Table S6). While most of the locus pairs did not show significant deviation from linkage equilibrium, one pair of loci in the H06 and J02 populations was in LD after applying the Bonferroni correction $(P>0.01)$ (Additional file 1: Table S7). All pair wise $F_{\mathrm{ST}}$ estimates were significantly different from zero $(P<0.05)$. Genetic differentiation between all pairs of
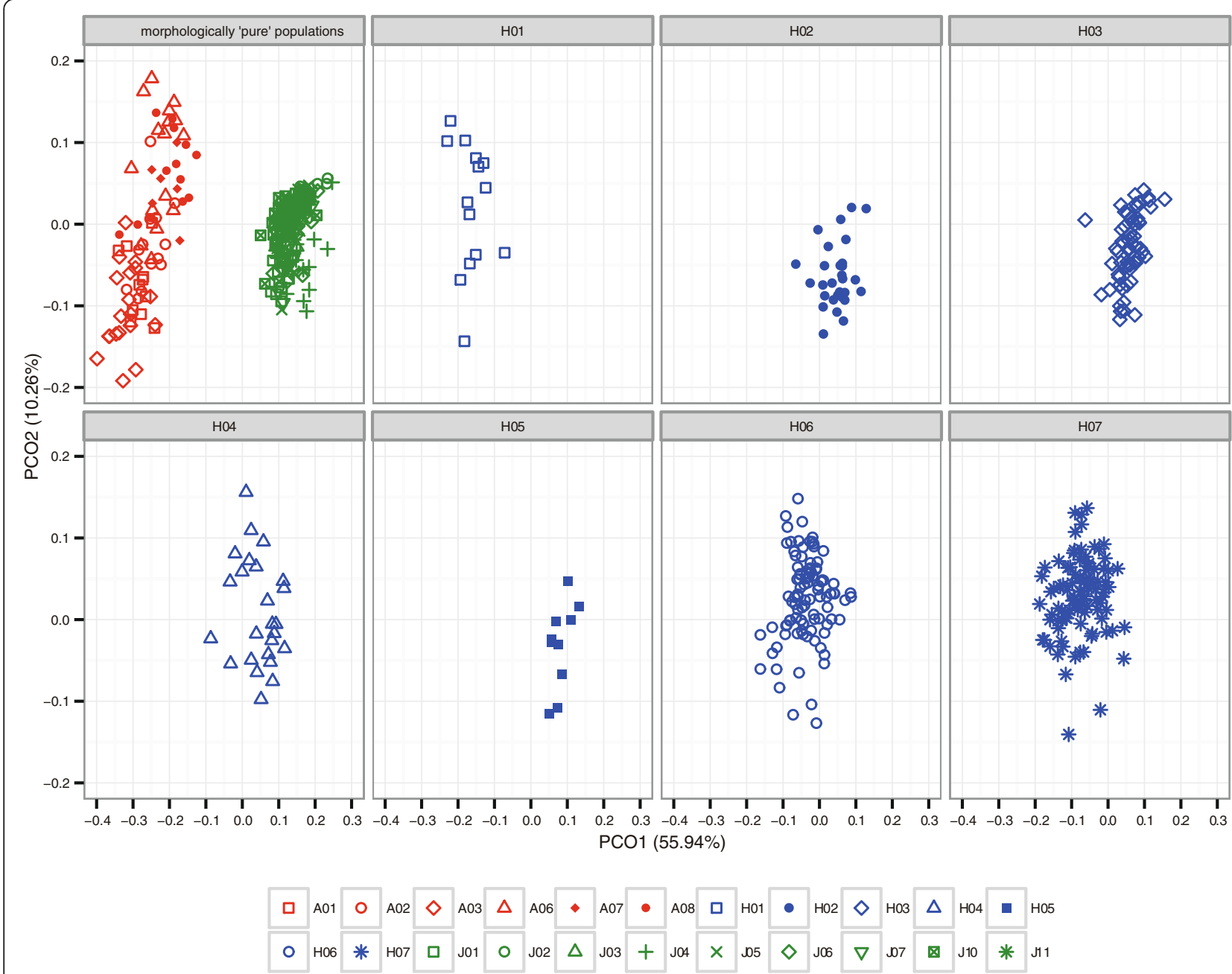

Fig. 3 Principle coordinate analysis of 11 morphological characteristics of individuals from morphologically 'pure' $V$. atratum and $V$. japonicum plants and morphologically intermediate plants 
$V$. atratum and $V$. japonicum populations were moderate or large with $F_{\mathrm{ST}}$ values ranging from 0.18 to 0.52 (Additional file 1: Table S8).

\section{Population genetic structure}

The best value for the number of genetic clusters $(K)$ determined from STRUCTURE analysis was 2 based on $\Delta K$ values (Additional file 1: Figure S4 and Fig. 4). The optimal $K$ value determined using the TESS program was 5 based on the deviance information criterion (DIC). Because we focused on hybridization between the two species in this study, we adopted $K=2$ a priori, even when using TESS. With $K=2$, all morphologically 'pure' $V$. atratum populations and the J01-J08 V. japonicum populations clustered into two separate groups (Fig. 4). In contrast, most individuals of the morphologically 'pure' $V$. japonicum J09-J11 populations were assigned to $V$. atratum or considered admixed individuals. A large number of the individuals in the morphologically putative hybrid $\mathrm{H} 02, \mathrm{H} 03, \mathrm{H} 04$, and $\mathrm{H} 05$ populations were assigned to $V$. japonicum, whereas most of the individuals in the $\mathrm{H} 06$ and $\mathrm{H} 07$ populations were assigned to $V$. atratum. Many of the H01 individuals were considered to be admixed individuals (Fig. 4, Additional file 1: Table S9). Because of the relatively small number of microsatellite loci used, the Bayesian-based assignment approach may have assigned highly backcrossed individuals (which genetically resemble the parental form) to either of the parental categories. Discriminant analysis of principal components (DAPC) also identified all morphologically 'pure' $V$. atratum individuals and the $V$. japonicum J01-J08 populations as well-delimited genotype clusters (Fig. 5). Individuals of the introgressed $V$. japonicum populations (J09-J11) were distributed over intermediate positions near $V$. japonicum. In the H01, H06, and H07 putative hybrid populations, individuals were distributed over intermediate positions near $V$. atratum, whereas individuals of the $\mathrm{H} 02-\mathrm{H} 05$ populations were distributed over intermediate positions near V. japonicum.

\section{Long-term estimates of gene flow}

Coalescent-based estimates obtained from the LAMARC program indicated that $4 \mathrm{Nm}$ 'pure' $V$. atratum $\rightarrow$ 'pure' $V$. japonicum

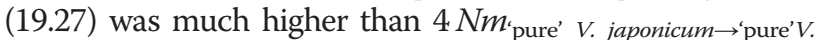
atratum (1.18) (Additional file 1: Table S10). In addition, there was no evidence of unequal amount genetic input into the putative hybrid population, because of overlapping CIs for estimates of $4 \mathrm{Nm}$ in both directions.

\section{Species distribution modeling}

SDM based on Community Climate System Model version 4 (CCSM4) data at the time of the LGM is shown in Fig. 6. SDM for both $V$. atratum and $V$. japonicum had high predictive performance with AUC values of 0.995 and 0.997 , respectively. The predicted current potential distribution range was mostly consistent with known field observations and herbarium records in Japan. The potential ranges of both species in Japan during the LGM were apparently contracted compared to the present ranges. During the LGM, $V$. atratum was distributed mainly in the entire western part of Japan and along the Japan Sea side of Honshu. After the LGM, suitable habitats for $V$. atratum expanded gradually across most of Honshu. In addition, during the LGM, $V$. japonicum was restricted to possible southern refugia, mainly at the southern tip of Kyushu and in a narrow coastal belt of the Pacific side of Honshu. After the LGM, $V$. japonicum subsequently expanded its range across western Japan and some parts of eastern Japan. In addition, the predicted distribution ranges of $V$. atratum and $V$. japonicum in the Japanese Archipelago for the mid-Holocene did not differ substantially from the present distribution ranges.

\section{Discussion}

Shifts in the ranges of V. atratum and V. japonicum with climate change

The potential ranges of $V$. atratum and $V$. japonicum predicted by SDM suggested that these two ecologically distinct species responded to climate changes in

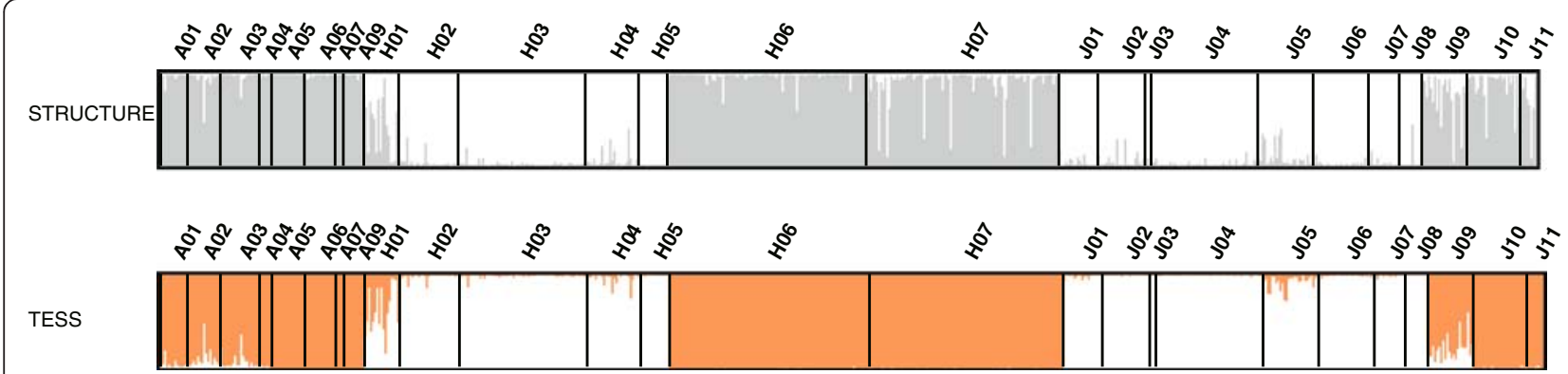

Fig. 4 Admixture analysis showing the proportion of the genome of each individual originating from $V$. atratum or $V$. japonicum using the programs STRUCTURE and TESS. Each individual is represented as a vertical bar indicating the assignment score of each genetic group 


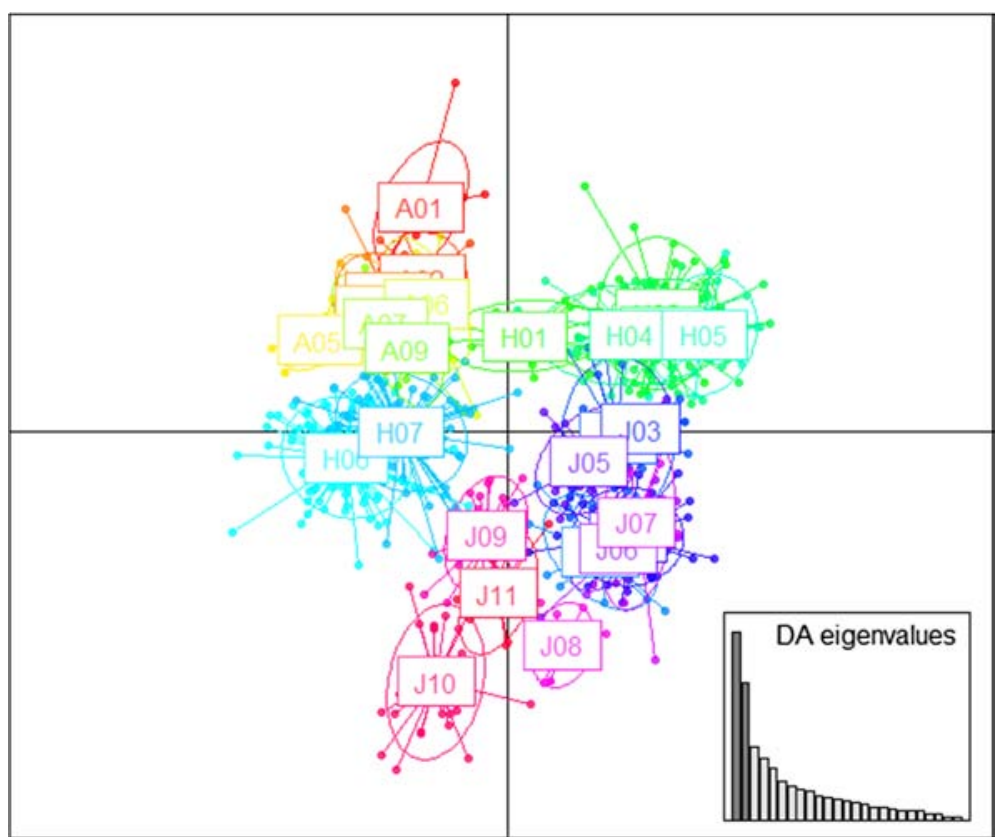

Fig. 5 Discriminant analysis of principal components (DAPC) based on microsatellite data sets

different ways across the Japanese Archipelago (Fig. 6). During the LGM, $V$. atratum was distributed mainly in the entire western part of Japan and along the Japan Sea side of Honshu, whereas $V$. japonicum was restricted to possible southern refugia, mainly at the southern tip of Kyushu and in a narrow coastal belt of the Pacific side of Honshu. During the warmer post-glacial period, $V$. atratum expanded its range across most of the territory of Honshu, whereas $V$. japonicum expanded its range across western Japan and some parts of eastern Japan.

\section{Consequences of secondary contact and patterns of} hybridization between V. atratum and V. japonicum

Morphological data confirmed the putative hybridization between $V$. atratum and $V$. japonicum. Morphologically 'pure' $V$. atratum and $V$. japonicum were readily discriminated based on the PCO analysis (Fig. 3) and variations in composite traits (Additional file 1: Figure S2S3). All putative hybrid populations exhibited intermediate and/or parental-like phenotypes; however, morphological investigation alone is insufficient to explain gene flow-mediated hybridization patterns $[63,64]$. We also used microsatellite markers to examine the genetic structure of hybrid populations. The Bayesian-based clustering analysis of nuclear microsatellite markers using STRUCTURE showed that the optimal value of $K$ was 2 corresponding to the two morphologically 'pure' $V$. atratum populations and part of the morphologically 'pure' populations of $V$. japonicum (J01-J08) (Fig. 4). In the putative hybrid populations, most individuals exhibited $V$. atratum-like genotypes (H06 and H07), V. japonicum-like genotypes $\mathrm{H} 02-\mathrm{H} 05$ and admixed genotypes (H01). The DAPC of all individuals again showed two genetically distinct groups as did analysis based on STRUCTURE (Fig. 5). The H01, H06, and $\mathrm{H} 07$ populations were genetically closer to $V$. atratrum, whereas the $\mathrm{H} 02-\mathrm{H} 05$ populations were genetically closer to $V$. japonicum.

Most hybrid populations (H02-H05 and H06-H07) consist with parental-like genotypes. These genotypes may be generated by frequent backcrossing to one of parental species, because highly backcrossed individuals are difficult to distinguish from parental individuals due to the relatively small number of loci [65]. Unidirectional backcrossing might be explained by reproductive system [8-11] and/or relative species abundance [12]. Following reasons are possible to explain the fact. First, factors driving unidirectional backcrossing in plants usually include differences in flower structure [8], flowering time [9] and mating system [10] among interfertile species, differences in the offspring fitness of reciprocal crosses [12]. In the present study, there is no difference in flower structure, flowering time and mating system between $V$. atratum and $V$. japonicum. In addition, biases in offspring fitness unlikely exist, because both $V$. atratum-like genotypes (H06 and H07), V. japonicum-like genotypes $\mathrm{H} 02-\mathrm{H} 05$ and admixed genotypes (H01) were detected. Alternatively, the unidirectional backcrossing might result from 'pollen swamping' by more abundant local species over later-colonizing species [66-68]. The colonizing species may have been subject to substantial pollen flow from the local species and repeated backcrosses with incoming pollen would generate abundant 


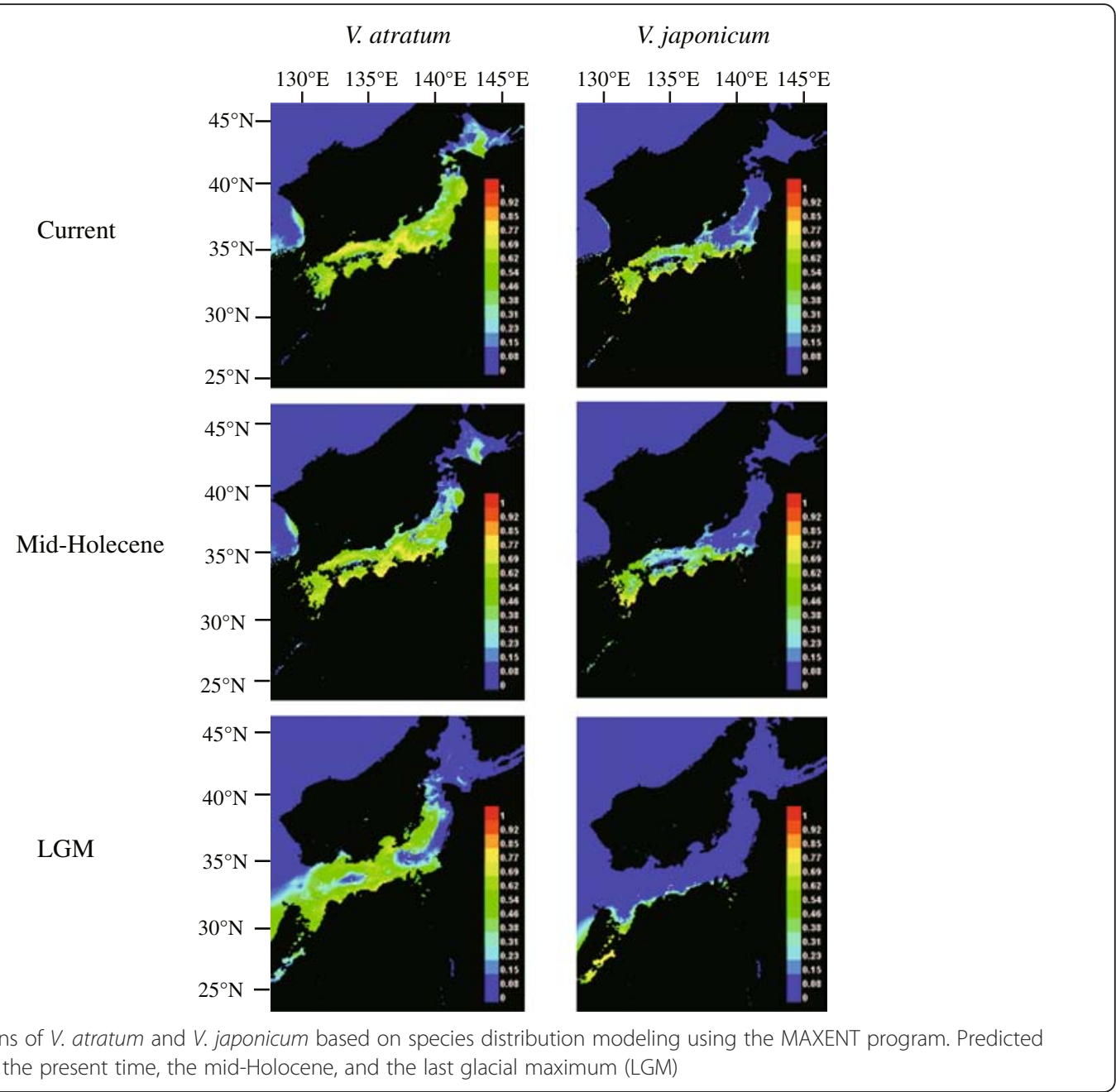

backcrossing to the local aboriginal species. Genetic constitutions of hybrid populations H06 and H07 can be explained by the prediction of colonization process (Fig. 6); during the LGM, $V$. atratum were already distributed in the area where the current $\mathrm{H} 06$ and $\mathrm{H} 07$ populations are located. After the glacial period, V. japonicum may have colonized this area from its southern refugia and been subject to substantial pollen flow from $V$. atratum. If backcrosses to $V$. atratum are selectively favored and do not exhibit reduced fitness relative to $V$. japonicum and $V$. atratum, they may ultimately displace 'pure' populations of $V$. japonicum and $V$. atratum.

Although the SDM results indicated that $V$. atratum colonized the area where the current $\mathrm{H} 01-\mathrm{H} 05$ populations were located earlier than $V$. japonicum (Fig. 6), the genetic constitutions of the $\mathrm{H} 01-\mathrm{H} 05$ populations differed from those of the $\mathrm{H} 06$ and $\mathrm{H} 07$ populations (Fig. 5). We consider that the genetic constitutions of these hybrid populations between two Vincetoxicum were influenced not only by the historical colonization process, but were also regulated by other factor, such as, abiotic environmental regimes. Variation in fine-scale habitats might promote differences in the strengths of selection on recombination genotypes and lead to variable spatial structure in a narrow region [15-22]. In the present study, population H01 show different genetic constitution with population H02-H05. During field investigation, we found hybrid populations $\mathrm{HO1}$ located in high cliff, whereas population H02-H05 located in rocky beaches. Thus, population $\mathrm{H} 01$ and $\mathrm{H} 02-\mathrm{H} 05$ may have suffered different ecological selection and show different genetic constitution.

\section{Long-term hybrid swarm persistence}

Hybrid swarms are believed to persist through two mechanisms $[5,69]$. They may be maintained by frequent and strong gene flow that counterbalances selection against the hybrids. Alternatively, they may be self-sustaining and maintained largely by selective advantage. The hybridization between the two Vincetoxicum species undoubtedly falls into the latter circumstance. First, LD was observed in almost no combinations of loci 
in the hybrid populations (Additional file 1: Table S7) suggesting that the hybrid populations are not maintained by ongoing genetic input from parental populations and may have persisted for several generations. These attributes are characteristic of a hybrid swarm where the hybrids are self-sustaining [70]. Second, the pollen fertility of all individuals in the hybrid populations was very high (Additional file 1: Table S5) providing high viability to facilitate mating between the individuals. Combined with the SDM results (Fig. 6), which predicted probable secondary contact during the post-glacial period, one possible scenario to account for the existence of the hybrid swarm is that the hybrid populations probably formed when $V$. atratum and $V$. japonicum came into contact during the post-glacial period and may be self-sustaining and have persisted for a long term - since $V$. atratum and $V$. japonicum came into contact during the post-glacial period.

\section{Historic introgression}

The Bayesian-based clustering analyses showed signs of introgressive hybridization (Fig. 5). In the J09-J11populations, the morphologically 'pure' $V$. japonicum population was composed of genetic clusters of both $V$. atratum and $V$. japonicum. Coalescent-based estimates from LAMARC also indicated high historic gene flow among 'pure' $V$. atratum and 'pure' $V$. japonicum populations (Additional file 1: Table S10). The modeled distribution shows that during LGM, suitable habitat for $V$. japonicum J09-J11 populations still persist in where they exist currently. There would have been a situation that small $V$. japonicum populations continued to persist in the area (where J09-J11 are located currently) surrounded by much larger populations of $V$. atratum, resulting in directional introgression from the latter species.

\section{Discrepancy in morphological and genetic identification of hybridity}

The morphologies of individuals in the $\mathrm{H} 06$ and $\mathrm{H} 07$ hybrid populations were intermediate between those of $V$. atratum and $V$. japonicum (Fig. 3 and Additional file 1: Figure S2). Surprisingly, almost no individuals exhibited intermediate genotypes based on the results of microsatellite analyses (Fig. 4). A probable cause of this discrepancy is that morphology may be controlled by numerous genes, whereas a relatively small number of microsatellite loci were employed in the Bayesian-based assignment approach. Thus, microsatellite genotypes may be rapidly fixed to one of the parental species genotypes by backcrossing. However, the genes affecting morphology may have persisted over longer periods of time.

\section{Conclusions}

In this study, we demonstrated that climatic oscillations during the Quaternary period likely led to species range shift and subsequently secondary contact. We confirmed the hybridization between $V$. atratum and $V$. japonicum. Hybrid populations may be self-sustaining and have persisted since $V$. atratum and $V$. japonicum came into contact during the post-glacial period. Moreover, our findings show that the pattern of hybridization between $V$. atratum and $V$. japonicum is unidirectional and differs among populations. In addition, Bayesian-based clustering analysis and coalescent-based estimates of long-term gene flow showed patterns of introgressive hybridization in three morphologically 'pure' $V$. japonicum populations. We concluded that these differences in the genetic consequences of secondary contact are caused by historical colonization processes and/or natural selection.

\section{Availability of supporting data}

The datasets supporting the results of this article are available in the Dryad (doi:10.5061/dryad.mg5rs).

\section{Additional file}

\begin{abstract}
Additional file 1: Figure S1. Map showing presence data for $V$. atratum (filled purple circles) and $V$. japonicum (filled yellow circles) populations used in niche modelling. Figure S2. Box-plots showing inter- and infra-population variation distribution in nine morphology character in each population. Rectangles define $25 \%$ and $75 \%$ quartiles (lower and upper edges of the box). Horizontal bar within box present the median. Whiskers extend up to the 90th percentiles and down to the 10th percentiles. Closed circle show outliers. Figure S3. Bar plot showing the inter- and infra-population variation pattern of hair density on leaf and corolla surface. Figure S4. Bayesian inference of the most likely number of clusters in the STRUCTURE analysis. (a) Plot of mean likelihood logarithmic probability of the data using 10 replicates runs at each value of $K(K=1-10)$. (b) Distribution of delta $K$ for each $K$ estimated from following Evanno et al. (2005). Figure S5. Deviance Index Criterion (DIC) for TESS analyses. Table S1. Details of the sample locations, sample size $(N)$ and genetic diversity measure $\left(N_{\mathrm{a}}\right.$ : mean number of alleles per locus, $H_{\mathrm{E}}$ : expected heterozygosity, $H_{\mathrm{O}}$ : observed heterozygosity, AR: allele richness, PAR: private allele richness). Table S2. Description and references for the 10 nuclear SSR loci employed in this study. Table S3. Presence data used in niche modelling. Table S4. Bioclimatic variables obtained from the WorldClim

and the variables used for predicting the distribution of $V$. atratum and $V$. japonicum. Table S5. Pollen fertility examined in the studied Vincetoxicum populations. Percentages of fertile pollen grains per population expressed as minimum, maximum and median. Table S6. Inbreeding coefficient for all populations at each microsatellite loci. Table S7. Linkage disequilibrium between all pairs of loci in each population. Significant $P$-values are given in bold after Bonferroni corrections (Rice 1989). Table S8. Pairwise estimates of genetic differentiation $\left(F_{S T}\right)$ between populations base on 10 microsatellite markers. Table S9. Assignment individuals based on result of STRUCTURE. Table S10. Estimates of gene flow (4Nm) among 'pure' V. atratum (A01-A07 and A09), 'pure' V. japonicum (J01-J08), introgressed V. japonicum (J09-J11), north group of putative hybrid populations $(\mathrm{H} 01-\mathrm{H} 05)$ and south group of putative hybrid populations ( $\mathrm{H06}$ and $\mathrm{H} 07$ ). Source populations are listed by column, recipient populations listed by row. (DOCX 928 kb)
\end{abstract}

\section{Competing interests}

The authors declare that they have no competing interests.

\section{Authors' contributions}

MM and FT collected samples, MM conceived and designed the experiments, FT and YL performed the experiments. YL and TY analyzed the data, and YL, TY and MM wrote the manuscript. All authors read and approved the final manuscript. 


\section{Acknowledgments}

We thank Dr. S. Horie for technical advice and Mr. Y. Takahashi for sampling. We also thank the anonymous reviewers for helpful comments on the manuscript. This work was conducted under the framework of the "Precise Impact Assessments on Climate Change" of the Program for Risk Information on Climate Change (SOUSEl Program) supported by the Ministry of Education, Culture, Sports, Science, and Technology-Japan (MEXT). This study was also supported by a Grant-in-Aid to MM from the Japan Society for the Promotion of Science (JSPS KAKENHI 21570086, http://www.jsps.go.jp) and the Tohoku University Global Centre of Excellence (GCOE) Program "Center for Ecosystem Management Adapting to Global Change" (J03).

\section{Author details}

'Botanical Gardens, Tohoku University, Sendai, Aoba 980-0862, Japan. ${ }^{2}$ Division of Ecology and Evolutionary Biology, Graduate School of Sciences, Tohoku University, Sendai, Aoba 980-8578, Japan. ${ }^{3}$ Department of Life Science, Faculty of Integrated Arts and Sciences, The University of Tokushima, Minami-jyosanjima, Tokushima 770-8502, Japan.

\section{Received: 23 September 2015 Accepted: 12 January 2016}

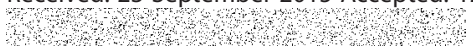

\section{References}

1. Comes HP, Kadereit JW. The effect of quaternary climatic changes on plant distribution and evolution. Trends Plant Sci. 1998;3(11):432-8.

2. Davis MB, Shaw RG. Range shifts and adaptive responses to Quaternary climate change. Science. 2001;292(5517):673-9.

3. Taberlet P, Fumagalli L, Wust-Saucy A, Cosson J. Comparative phylogeography and postglacial colonization routes in Europe. Mol Ecol. 1998;7(4):453-64

4. Hewitt GM. Speciation, hybrid zones and phylogeography - or seeing genes in space and time. Mol Ecol. 2001;10(3):537-49.

5. Arnold ML. Natural hybridization and evolution. New York: Oxford University Press; 1997.

6. Coyne JA, Orr HA. Speciation. 37th ed. Sunderland: Sinauer Associates; 2004

7. Petit RJ, Excoffier L. Gene flow and species delimitation. Trends Ecol Evol. 2009;24(7):386-93.

8. Field DL, Ayre DJ, Whelan RJ, Young AG. Patterns of hybridization and asymmetrical gene flow in hybrid zones of the rare Eucalyptus aggregato and common E. rubida. Heredity. 2011;106(5):841-53.

9. Milne Rl, Abbott RJ. Reproductive isolation among two interfertile Rhododendron species: low frequency of post-F1 hybrid genotypes in alpine hybrid zones. Mol Ecol. 2008;17(4):1108-21.

10. Wallace LE, Culley TM, Weller SG, Sakai AK, Kuenzi A, Roy T, et al. Asymmetrical gene flow in a hybrid zone of Hawaiian Schiedea (Caryophyllaceae) species with contrasting mating systems. PLoS One. 2011;6(9):e24845.

11. Natalis LC, Wesselingh RA. Post-pollination barriers and their role in asymmetric hybridization in Rhinanthus (Orobanchaceae). Am J Bot. 2012 99(11):1847-56.

12. Lepais O, Petit RJ, Guichoux E, Lavabre JE, Alberto F, Kremer A, et al. Species relative abundance and direction of introgression in oaks. Mol Ecol. 2009; 18(10):2228-42.

13. Currat M, Ruedi M, Petit RJ, Excoffier $L$. The hidden side of invasions: massive introgression by local genes. Evolution. 2008;62(8):1908-20.

14. Petit RJ, Bodénès $C$, Ducousso A, Roussel G, Kremer A. Hybridization as a mechanism of invasion in oaks. New Phytol. 2004;161(1):151-64.

15. Cruzan MB, Arnold ML. Ecological and genetic associations in an Iris hybrid zone. Evolution. 1993;47(5):1432-45.

16. Hatfield T, Schluter D. Ecological Speciation in Sticklebacks: EnvironmentDependent Hybrid Fitness. Evolution. 1999:53(3):866-73.

17. Hochwender CG, Fritz RS. Fluctuating asymmetry in a Salix hybrid system: The importance of genetic versus environmental causes. Evolution. 1999; 53(2):408-16.

18. Johansen-Morris AD, Latta RG. Genotype by environment interactions for fitness in hybrid genotypes of Avena barbata. Evolution. 2008:62(3):573-85.

19. Johnston JA, Grise DJ, Donovan LA, Arnold ML. Environment-dependent performance and fitness of Iris brevicaulis, I. fulva (Iridaceae), and hybrids. Am J Bot. 2001;88(5):933-8

20. Karrenberg S, Favre A. Genetic and ecological differentiation in the hybridizing campions Silene dioica and S. latifolia. Evolution. 2008;62(4):763-73.
21. Rieseberg $L H$, Sinervo B, Linder $C R$, Ungerer MC, Arias DM. Role of gene interactions in hybrid speciation: evidence from ancient and experimenta hybrids. Science. 1996;272(5652):741-4.

22. Ross RIC, Agren JA, Pannell JR. Exogenous selection shapes germination behaviour and seedling traits of populations at different altitudes in a Senecio hybrid zone. Ann Bot-London. 2012;110(7SI):1439-47.

23. Ono Y, Igarashi Y. Natural history of Hokkaido. Hokkaido: Hokkaido University Press; 1991.

24. Fujii N, Tomaru N, Okuyama K, Koike T, Mikami T, Ueda K. Chloroplast DNA phylogeography of Fagus crenata (Fagaceae) in Japan. Plant Syst Evol. 2002; 232(1-2):21-33.

25. Sugahara K, Kaneko Y, Ito S, Yamanaka K, Sakio H, Hoshizaki K, et al. Phylogeography of Japanese horse chestnut (Aesculus turbinata) in the Japanese Archipelago based on chloroplast DNA haplotypes. J Plant Res. 2011:124(1):75-83.

26. Tono A, Iwasaki T, Seo A, Murakami N. Environmental factors contribute to the formation and maintenance of the contact zone observed in deciduous broad-leaved tree species in Japan. J Plant Res. 2015;128(4):535-51.

27. Qi X, Yuan N, Comes H, Sakaguchi S, Qiu Y. A strong 'filter' effect of the East China Sea land bridge for East Asia's temperate plant species: inferences from molecular phylogeography and ecological niche modelling of Platycrater arguta (Hydrangeaceae). BMC Evol Biol. 2014;14(1):41.

28. Mimura M, Mishima M, Lascoux M, Yahara T. Range shift and introgression of the rear and leading populations in two ecologically distinct Rubus species. BMC Evol Biol. 2014;14:209.

29. Toyama H, Yahara T. Comparative phylogeography of two closely related Viola species occurring in contrasting habitats in the Japanese archipelago. J Plant Res. 2009:122(4):389-401.

30. Lee S, Maki M. Comparative phylogeographic study of Hosta sieboldiana and Hosta albomarginata (Asparagaceae) in Japan. Ecol Evol. 2013;3(14):4767-85.

31. Saeki I, Dick CW, Barnes BV, Murakami N. Comparative phylogeography of red maple (Acer rubrum L.) and silver maple (Acer saccharinum L.): impacts of habitat specialization, hybridization and glacial history. J Biogeogr. 2011; 38(5):992-1005.

32. Yamazaki T. Asclepiadaceae. In: Iwatsuki K, Yamazaki T, Boufford D, Ohba H, editors. Flora of Japan. 3ath ed. Tokyo: Kodansha; 1993. p. 168-82

33. Yamashiro T, Yamashiro A, Yokoyama J, Maki M. Morphological aspects and phylogenetic analyses of pollination systems in the Tylophora-Vincetoxicum complex (Apocynaceae-Asclepiadoideae) in Japan. Biol J Linn Soc. 2008; 93(2):325-41.

34. Yamashiro T, Fukuda T, Yokoyama J, Maki M. Molecular phylogeny of Vincetoxicum (Apocynaceae-Asclepiadoideae) based on the nucleotide sequences of cpDNA and nrDNA. Mol Phylogenet Evol. 2004;31(2):689-700.

35. Chakraborty R, Weiss KM. Admixture as a tool for finding linked genes and detecting that difference from allelic association between loci. Proc Natl Acad Sci U S A. 1988;85(23):9119-23.

36. Briscoe D, Stephens JC, O'Brien SJ. Linkage disequilibrium in admixed populations: applications in gene mapping. J Hered. 1994;85(1):59-63.

37. Goodman SJ, Barton NH, Swanson G, Abernethy K, Pemberton JM, Goodman SJ, et al. Introgression through rare hybridization: A genetic study of a hybrid zone between red and sika deer (genus Cervus) in Argyll, Scotland. Genetics. 1999;152(1):355-71.

38. Maki M, Horie S, Yokoyama J. Comparison of genetic diversity between narrowly endemic shrub Menziesia goyozanensis and its widespread congener M. pentandra (Ericaceae). Conserv Genet. 2002;3(4):421-5.

39. Tada F, Yamashiro T, Maki M. Development of microsatellite markers for the endangered grassland perennial herb Vincetoxicum atratum (ApocynaceaeAsclepiadoideae). Conserv Genet. 2009;10(4):1057-9.

40. Nakahama N, Kaneko S, Hayano A, Isagi Y, Inoue-Murayama M, Tominaga T. Development of microsatellite markers for the endangered grassland species Vincetoxicum pycnostelma (Apocynaceae) by using next-generation sequencing technology. Conserv Genet Resour. 2012;4(3):669-71.

41. R Development Core Team. R: A Language and environment for statistical computing. Vienna: R Foundation for Statistical Computing; 2012.

42. Li Y, Itoi T, Takahashi H, Maki M. Morphological and genetic variation in populations in a hybrid zone between Leucosceptrum japonicum and $L$. stellipilum (Lamiaceae) in the central Japanese mainland. Plant Syst Evol. 2015:301(3):1029-41.

43. Peakall R, Smouse PE. GenAlEx 6.5: genetic analysis in Excel. Population genetic software for teaching and research-an update. Bioinformatics. 2012 28(19):2537-9. 
44. Kalinowski ST. Hp-rare 1.0: A computer program for performing rarefaction on measures of allelic richness. Mol Ecol Notes. 2005;5(1):187-9.

45. Weir BS, Cockerham CC. Estimating F-Statistics for the Analysis of Population Structure. Evolution. 1984;38(6):1358-70.

46. Excoffier $\mathrm{L}$, Lischer $H$. Arlequin suite ver 3.5: a new series of programs to perform population genetics analyses under Linux and Windows. Mol Ecol Resour. 2010;10(3):564-7.

47. Rousset F. genepop'007: a complete re-implementation of the genepop software for Windows and Linux. Mol Ecol Resour. 2008;8(1):103-6.

48. Pritchard JK, Stephens M, Donnelly P. Inference of population structure using multilocus genotype data. Genetics. 2000;155(2):945-59.

49. Chen C, Durand E, Forbes F, François O. Bayesian clustering algorithms ascertaining spatial population structure: a new computer program and a comparison study. Mol Ecol Notes. 2007;7(5):747-56.

50. Earl DA. STRUCTURE HARVESTER: a website and program for visualizing STRUCTURE output and implementing the Evanno method. Conserv Genet Resour. 2012;4(2):359-61.

51. Jakobsson M, Rosenberg NA. CLUMPP: a cluster matching and permutation program for dealing with label switching and multimodality in analysis of population structure. Bioinformatics. 2007;23(14):1801-6.

52. Rosenberg NA. DISTRUCT: a program for the graphical display of population structure. Mol Ecol Notes. 2004:4(1):137-8.

53. Jombart $\mathrm{T}$. adegenet: a R package for the multivariate analysis of genetic markers. Bioinformatics. 2008;24(11):1403-5.

54. Kuhner MK. LAMARC 2.0: maximum likelihood and Bayesian estimation of population parameters. Bioinformatics. 2006;22(6):768-70.

55. Kimura M, Ohta T. Stepwise mutation model and distribution of allelic frequencies in a finite population. Proc Natl Acad Sci U S A. 1978;75(6):2868-72.

56. Rambaut A, Suchard MA, Xie D, Drummond AJ: Tracer v1.6. Available at http://beast.bio.ed.ac.uk/Tracer. 2014.

57. Hijmans RJ, Cameron SE, Parra $J \mathrm{~L}$, Jones $\mathrm{PG}$, Jarvis A. Very high resolution interpolated climate surfaces for global land areas. Int J Climatol. 2005; 25(15):1965-78

58. Hijmans RJ, Guarino L, Cruz M, Rojas E. Computer tools for spatial analysis of plant genetic resources data: 1. DIVA-GIS. Plant Genet Resour Newsl. 2001; 127:15-9.

59. Phillips SJ, Dudík M. Modeling of species distributions with Maxent: new extensions and a comprehensive evaluation. Ecography. 2008;31(2):161-75.

60. Fawcett T. An introduction to ROC analysis. Pattern Recogn Lett. 2006;27(8): 861-74.

61. Fielding $\mathrm{AH}$, Bell JF. A review of methods for the assessment of prediction errors in conservation presence/absence models. Environ Conserv. 1997;24(01):38-49.

62. Swets JA. Measuring the accuracy of diagnostic systems. Science. 1988; 240(4857):1285-93.

63. Hardig TM, Brunsfeld SJ, Fritz RS, Morgan M, Orians CM. Morphological and molecular evidence for hybridization and introgression in a willow (Salix) hybrid zone. Mol Ecol. 2000;9(1):9-24.

64. Tsukaya H, Fukuda T, Yokoyama J. Hybridization and introgression between Callicarpa japonica and C. mollis (Verbenaceae) in central Japan, as inferred from nuclear and chloroplast DNA sequences. Mol Ecol. 2003:12(11):3003-11.

65. Boecklen WJ, Howard DJ. Genetic Analysis of Hybrid Zones: Numbers of Markers and Power of Resolution. Ecology. 1997;78(8):2611-6.

66. Ellstrand NC, Elam DR. Population Genetic Consequences of Small Population Size: Implications for Plant Conservation. Annu Rev Ecol Syst. 1993;24(1):217-42.

67. Levin DA, Francisco-Ortega J, Jansen RK. Hybridization and the Extinction of Rare Plant Species. Conserv Biol. 1996;10(1):10-6.

68. Rhymer JM, Simberloff D. Extinction by Hybridization and Introgression. Annu Rev Ecol Syst. 1996:27:83-109.

69. Anderson E. Hybridization of the Habitat. Evolution. 1948;2(1):1-9.

70. Latch EK, Kierepka EM, Heffelfinger JR, Rhodge OE. Hybrid swarm between divergent lineages of mule deer (Odocoileus hemionus). Mol Ecol. 2011; 20(24):5265-79.

\section{Submit your next manuscript to BioMed Central and we will help you at every step:}

- We accept pre-submission inquiries

- Our selector tool helps you to find the most relevant journal

- We provide round the clock customer support

- Convenient online submission

- Thorough peer review

- Inclusion in PubMed and all major indexing services

- Maximum visibility for your research

Submit your manuscript at www.biomedcentral.com/submit
Biomed Central 